\title{
INFLUENCE OF PARENTAGE UPON INFANTILE MORTALITY.
}

\author{
By MISS ERIS EVANS, M.13.rond.
}

THE significance of the present high rate of infantile mortality cannot 1 be appreciated unless considered in relation to the birth-rate and death-rate of the whole population.

By infantile mortality rate is meant the proportion of infant deaths under twelve montlis to 1,000 births.

The birth-rate has been falling steadily since 1876 , when it was 36.3 - per 1,000 , and in 1907 reached $26 \cdot 3$ per 1000 of the population at all ages (cf. Registrar General's Summary Report, p. V.) This is the lowest birth-rate on record in this country.

It has been argued that a falling birth-rate is desirable, inasmuch as it is accompanied by a falling deatli-rate. But it has been pointed out that this is only a passing phase due to the decline in the birth-rate leading to a larger proportion of deaths at ages of low mortality, and that if the birth-rate continues to decline this must in time lead to a larger proportion of aged persons who give a high death-rate ( $c f$. Dr. Walford's Report on Infantile Nortality, 1907). This has been the experience of France ( $c f$. McCleary, Infantile Mortality, footnote, p. (i). It is on this account that the high infantile mortality rate, combined with a falling birth-rate, is of national importance.

During the five years $1876-1880$ the inf:unt mortality rate was 145 . It rose until during the years $1896-1900$ it was 156 . Since 1899 , when it stood at 163, it has dropped, though in 19904 it rose again to 145 (cf. Registrar General's Report, 1906, pp. XXXIX., XL.) Last year it reached the low figure of 116 , the lowest figure on record in this country. This decrease is, however, less satisfactory when we learn from the Registrar General that it was due mainly to the wet and cool summer "which checked the rise in the rate of infantile mortality which usually occurs at that period of the year." This customary rise is due to diarrhœal disease.

In discussing the influence of parentage upon infantile mortality there are many factors to be considered.

1. Nationality.-Cumparing various countries they are found to stand in the following order, starting with thuse having the highest rates of 
infantile mortality: Russia, Hungary, Prussia, Italy, France, Japan, England and Wales, Switzerland, Denmark, Scotland, Anstralia, Ireland, Sweden, Norway, New Zealand ( $c f$. Newman, Infant Mortality p. 323). New Zealand has reached the low rate of 80 , as compared with 150 for England and Wales and 272 for Russia.

If various races living together, in crowded areas of large towns, be compared, it is found that Jews, Italians, Scotch and Irish have al lower mortality than the English. This lowever is probably due only indirectly to difference of race, the immediate cause being the fact that the parents among these races care for their infants to a greater extent than do the English living in the same districts (cf. Newman, Infant Mortality, p. 225; (xemrge R. Sims, The Black Stain, p. 130). This better care involves not only breast-feeding, probably the most importint factor of all, but also greater cleanliness, ete.

2. The Occupation of Mothers.-Much emphasis has been laid upon the evil of employing married women in factories, and factory work has been made responsible for the heavy death-rate from prematurity and immaturity. In the Registrar (ieneral's Report, 1906, p. 14, we find the

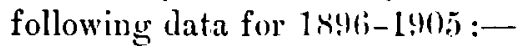

Lancashire (many women employed), inf:antile mortality rate 171

$\begin{array}{lllll}\text { (ilamorganshire }(f e w \text { women employed }) . . . & \ldots & \ldots & 167\end{array}$

$\begin{array}{llllllll}\text { Durham }(\operatorname{ditto}) & \ldots & \ldots & \ldots & \ldots & \ldots & \ldots & 164\end{array}$

$\begin{array}{lllll}\text { West Riding (many women enployed) } & \ldots & \ldots & \ldots & 158\end{array}$

In Preston and Blackburn, where the employment of women is declining, the infant mortality has been rising since 1891; and in Durham and S. Wales, where women are little employer, the infant mortality is rising; whereas in the West Riling, where women are much employed, the infant mortality is falling (eompare Nervsholme, Vital statistics, p. 127; Newman, Infant Mortality, p. 137).

It seems, therefore, that the employment of women is not the cause of high infantile mortality, but that both result from a common cause, and are therefore of ten found together. This common cause is probably the crowding of dense masses of population without means of support, leading to poor fool, clothing, and housing. This is suggested by the higher proportion of infant deaths from diarrhoea in urban districts (compare Newman, Infant Mortality, pp. 174, 197) "All diseases of infancy are heavier in the towns than the counties, but immaturity is twice as fatal and epidemic diarrhoua seven times as fatal in the towns."

A few mothers work away from home from choice, but these are a small proportion; the great majority go to work of necessity, because 
their husband's wages will not meet the needs of the family. To prohibit the women from working in factories must therefore lead to pourer feeding and poorer housing, or force the mother to undertake work other than factory work which may be heavier and more badly paid. Any of these results would lead to higher infant mortality.

3. Age Incidence of Marriage.-The mortality of children appears lowest when the mothers are between 30 and 35 years, greatest when they are under 20, and gradually increasing when they are over 3.5 , though even then lower than when between 20 and 30 years of agre. The influence of age of the father appears to act in the same direction. Inasmuch, however, as the higher age incidence of marriage is usually found among those having greatest sense of responsibility, it is possible that this factor may have greater influence than that of age ( $c f$. Newsholme, Vital Statistics, p. 129).

4. Mental Development of the Porents.-Illiteracy, measured by the inability to sign their name, is more marked in women than in men in large towns and less marked than in men in agricultural counties. Among the 22 counties with lowest infantile mortality (1891-1900) one only, Hereford, had more than 30 per 1,000 illiterate married women, the highest being Mommouth with 64 per 1,000 (ct: Newman, Infant Mortality, p. 222).

The question of illiteracy is a factor probably entering largely into the high infantile mortality rates of industrial areas. The ignorince of mothers in the science and art of mothering far exceeds the indication given by the inability to sign their names. Dr. Milson Rhodes asked tifty mill girls how they would feed a baby three months old deprived of its mother. One said cow's milk, one said milk and water, while the remaining forty-eight were entirely wrong.

The importance of mental development in the mother is illustrated in other ways. It is not merely a question of her knowledge of facts. That the mental state of the nursing mother may affect the health of the infant has been demonstrated by Paul Budin ( $f$. The Nursling, p. 89).

5. Alcoholism in the Parents. - The average number of children to each married woman admitted to reformatories under the Inebriates Act during 1905 and 1906 was $5 \cdot 3$ ( $c f$. Report of Inspector under Inebriates Act, p. 52). If this be compared with the legitimate birth-rate calculated on the married female population, aged 15-45 years, in England and Wales during 1906, which was 222 per 1,000 (cf. Registrar-General's Report, 1906 , p. XXIII.), it is seen that a most undesirable fertility exists among the inmates of reformatories. The child-mortality rate among these children of inebriates was 45.4 per cent., as compared with an infant 
mortality rate of 13 per cent. for England and Wales during the same period. The ages when the children of inebriates died is not given, but it appears clear that their death-rate is abnormally high.

These results may be compared with those of Dr. Sullivan in an inrestigation upon chronic female drunkards in the Liverpoul Prison who hat borne children. After excluding all cases complicated by other degeneriative factors ( $c f$. Newman, Infant Mortality, p. 72 ), the average number of children to each one of 120 such women was five. He compared these cases, where possible, with sober branches of the same family, with the result that 21 drunken mothers were found to have had an average of 5.95 children each, while 28 sober mothers of the same families had an average of 4.89 . The child mortality under two years for drunken mothers was $55 \cdot 2$ per cent. and for sober mothers $23 \cdot 9$ per cent.

It has been shown that alcoholism leads to physical deterioration in the child before birth, acting through the mother, as well as after birth through the environment of which it is the cause, whether the offender be father or mother ( $c f$. Newman, Infant Mortality, p. 72 ). If this fact be taken in conjunction with the high birth-rate among incbriates, as indicated by the above figures, the high death-rate among their children must be regarled as a preventive against racial degeneracy.

Illegitimacy.-The birth-rate of illegitimate children, though it gracklually fell from 18527 to 1900 , has been stationary since, while the birth-rate of legitimate children has continued to fall ( $c f$. Registrar General's Report, 1906, p. 5).

Infantile mortality from all causes in 1906 amounted to 261.35 pur 1,000 among illegitimate children as compared with 129.13 among legitimate children ( $c f$. Registrar General's Report, 1906, p. CXXX.) It alpears further, from the same report, that of the excess of cleaths in illegitimate children, a linrger proportion is due to prematurity and immiturity than to diarrhoca, and that a greater proportion is due to atrophy, debility, marasmus, etc., i.e., to immaturity than to prematurity. Among legitimate children, on the other hand, more deaths are reported due to prematurity thim to inmaturity ( $f$. Newman, Infant Mortality, p. 211). This difference between legitimate and illegitimate children is more noticeable when London only is taken ( $c f$. Report of Interdepartmental Committee on Physical Deterioration, 1904, Vol. I., p. 137).

These figures indicate that the ligh mortality among illegitimate children is due to prenatal causes rather than to environment, and if so, all remedies dirceted to lessening mortality among such infants tend to racial degeneracy. An exact comparison cannot be made owing to the difficulty 
in differentiating wasting due to immaturity from wasting due to neglect. In either case, however, it is an indication of inferior parentage.

Prostitution.-Dr. Sanger ( $c \%$. History of Prostitution, p. 477) states that as a result of answers obtained from 2,000 prostitutes in New York it was found that 947 had 1,917 children. One singly woman gave lirth to as many as ten children. Of the total 1,417 children 1,090 were illegitimate. There were more than six deaths to every ten children lorm as compared with one and three-quartes's to every ten children under five years for the whole of New York during three years.

The causes of death among these children of prostitutes is not given, but the proportion. of deaths rhe to immaturity is probably greater even than in the case of illegitimate children as a whole. Illegitimacy may be dissociated from prostitution particularly in rural districts, and in rural districts illegitimacy may be found associated with a low rate of infantile mortality (cf. Newman, Infant Mortality, footnote, 1. 25). It seems probable, therefore, that the high infantile mortality among illegitimate children is largely attributable to prostitution, and that liere especially it, acts as a preventive against racial degeneracy.

In order to jurge of the relative impurtance of various causes of infantile mortality we may compare the proportion of rlcaths clue to diarrhœal discases, respiratory diseases, wasting diseases, etc. (cf. Newman Infant Mortality, 1) 47 ; Registrar (iencral's Report, 1906, p. ('XVII.) The two great causes are wasting cliseases and diarrhoral diseases. The former occur chiefly before the third month and the latter chiefly after the third month. The former are clue chiefly to prenatal conditions, resulting in prematurity and immaturity, while the latter are due to conditions of environment. The former represent the infants which are born unfit to survive. As these so far exceed the deaths from any other single group of causes, and as we have found that deaths from immaturity predominate, particularly among illegitimate children and children of inebriates, it appears that if a satisfactory reduction is to be made in the rate of infantile mortality the advisability of allowing freedom to the criminal and inebriate classes must be considerel.

While it is urgently necessary that the questions of better housing, better milk supply, the economic position of mothers, and the elucation of mothers should receive immediate attention, it is also necessary to realize that while criminals, inebriates, and the feeble-minded continue to propagate, successful efforts in lowering the death-rate among children of such parents must lead to racial degeneracy. 